\title{
EFEKTIVITAS PROGRAM "BOTOLO'KU" TERHADAP PENINGKATAN PENGETAHUAN DAN SIKAP DALAM UPAYA PENGURANGAN SAMPAH BOTOL PLASTIK
}

\author{
Ishak $^{1)}$, Indra Amanah $\mathrm{AN}^{2)}$ \\ ${ }^{1}$ Kesehatan Masyarakat, Universitas Mega Buana Palopo (penulis 1) \\ Email: ishaknurlang@gmail.com \\ ${ }^{2}$ Kesehatan Masyarakat, Universitas Mega Buana Palopo (penulis 2) \\ Email: indra.amanah.andinurhayati@gmail.com
}

\begin{abstract}
ABSTRAK
Sampah (waste) diartikan sebagai sesuatu yang tidak digunakan, tidak dipakai, tidak disenangi, atau sesuatu yang dibuang, yang berasal dari kegiatan manusia dan tidak terjadi dengan sendirinya. Sampah botol plastik tidak bisa sepenuhnya diurai, butuh waktu hingga 100 tahun agar bisa diurai. Hal ini memberikan dampak buruk terhadap lingkungan. Hampir 3 juta ton sampah plastik diseluruh dunia berasal dari botol minum plastik yang hanya bisa digunakan sekali pakai. Volume sampah di Kota Palopo pada tahun 2017-2018 mengalami peningkatan. Pada tahun 2017 volume sampah mencapai 25.634 khusus sampah anorganik per harinya dan mengalami peningkatan ditahun 2018 yaitu sebanyak 28.046. Penelitian ini bertujuan untuk menilai efektivitas program Botolo'ku dalam pengurangan jumlah sampah botol plastik yang nantinya dapat diterapkan secara berkesinambungan di Kota Palopo. Penelitian ini menggunakan desain quasi eksperimental, dengan rancangan non equivalent control group design. Hasil penelitian menunjukkan untuk kelompok eksperimen diperoleh hasil uji t-test pengetahuan $p=0,00$ dan sikap $p=0,00$ yang artinya ada peningkatan pengetahuan dan sikap pada kelompok eksperimen sebelum dan sesudah diberikan Program "Botolo'ku” di Sekolah Kota Palopo, sedangkan untuk kelompok kontrol di peroleh hasil uji t-test pengetahuan $p=0,076$ dan sikap $p=0,171$ yang artinya tidak ada peningkatan pengetahuan dan sikap pada kelompok kontrol Program "Botolo'ku" di Sekolah Kota Palopo. Kesimpulan: Penerapan program "Botolo'ku” efektif dalam upaya pengurangan sampah botol plastik khususnya pada pengetahuan dan sikap siswa dalam mengurangi sampah botol plastik.
\end{abstract}

Kata Kunci: Pengetahuan, Sikap, Sampah

\begin{abstract}
Waste is defined as something that is not used, not used, disliked, or something that is discarded, which comes from human activities and does not happen by itself. Plastic bottle waste cannot meet the needs of being broken down, it takes up to 100 years to decompose. This has a negative impact on the environment. Nearly 3 million tonnes of plastic waste worldwide comes from single-use plastic drinking bottles. The volume of waste in Palopo City in 2017-2018 has increased. In 2017 the volume of waste reached 25,634, especially inorganic waste per day and an increase in 2018 was 28,046. This study aims to assess the Botolo'ku program in terms of the amount of plastic bottle waste that can be applied sustainably in Palopo City. This study used a quasi experimental design, with a non equivalent control group design. The results showed that for the experimental group the $t$ test results for knowledge were $p=0.00$ and attitude $p=0.00$, which means that there was
\end{abstract}


an increase in knowledge and attitudes in the experimental group before and after being given the "Botolo'ku" program at the Palopo City School. while for the control group the ttest results obtained for knowledge $p=0.076$ and attitude $p=0.171$, which means that there is no increase in knowledge and attitudes in the "Botolo'ku" program control group at Palopo City

School.

The application of the "Botolo'ku" program is effective in reducing plastic bottle waste, especially in the knowledge and attitudes of students in reducing plastic bottle waste.

Keywords:Knowledge, Attitude, Waste

\section{PENDAHULUAN}

Sampah menjadi salah satu permasalahan yang dialami oleh berbagai negara di dunia karena sifatnya yang sulit diurai, namun keberadaannya semakin meningkat setiap tahun. Masing-masing negara memiliki jumlah sampah yang berbeda dengan berbagai latar belakang penduduk dan kondisi negaranya (Azanella, 2019).

Masyarakat Indonesia hingga saat ini dikenal dengan kebiasaan menggunakan benda-benda yang terbilang praktis. Diantaranya adalah penggunaan kemasan makanan atau minuman sekali pakai. Tanpa disadari, kebiasaan ini semakin lama menimbulkan masalah terhadap menumpuknya limbah di lingkungan sekitar, serta kurangnya tingkat kesadaran masyarakat dalam mengolah limbah (Seizaria, 2017).

Produksi sampah setiap hari semakin meningkat seiring dengan bertambahnya jumlah produk dan pola konsumsi masyarakat (Sulistiyorini dkk, 2015). Berdasarkan data dari ScienceMag, jumlah produksi sampah plastik global sejak 1950 hingga 2015 cenderung selalu menunjukkan peningkatan. Pada 1950, produksi sampah dunia ada di angka 2 juta ton per tahun. Sementara 65 tahun setelah itu, pada 2015 produksi sampah sudah ada di angka 381 juta ton per tahun. Angka ini meningkat lebih dari 190 kali lipat, dengan rata-rata peningkatan sebesar 5,8 ton per tahun (Our World in Data).

Berdasarkan data dari Our World in Data, produksi sampah sepanjang 2015 di bidang industrial, dapat diklasifikasi menjadi beberapa jenis. Paling banyak produksi berasal dari sektor plastik kemasan produk yakni sebanyak 146 ton per tahun. Disusul dengan sampah di bidang bangunan dan konstruksi sebanyak 65 juta ton. Jenis sampah lainnya adalah tekstil, produk konsumsi dan institusional, transportasi, elektronik, dan mesin industri. 
Jurnal Kesehatan Karya Husada, No 9 Vol 1 Tahun 2021

PISSN 2337649X/EISSN 2655-8874

Ishak, Indra Amanah AN “Efektivitas Program "Botolo'ku” Terhadap Peningkatan Pengetahuan dan Sikap dalam Upaya Pengurangan Sampah Botol Plastik" (hal 11-22)

Di Indonesia sendiri, pemakaian kantong plastik dan kemasan pembungkus makanan juga berkontribusi sebagai penambah volume sampah disamping jenis-jenis sampah lainnya. Sampah yang tidak dikelola dan dibiarkan terus-menerus akan menimbulkan berbagai dampak bagi manusia dan lingkungan sekitar. Sampah jika dibuang ke sungai dapat menimbulkan pencemaran air, mengganggu ekosistem perairan, dan dapat menyebabkan banjir. Pembakaran plastik dapat menimbulkan polusi udara yang dapat merusak lingkungan dan kesehatan pernafasan. Oleh karena itu, diperlukan suatu pengelolaan yang tepat sehingga dapat mereduksi timbulan sampah yang dihasilkan oleh aktivitas sehari-hari (Kamali, Sumarlan, dan Fahrurazi, 2017).

Selain data Nasional, tingginya volume sampah juga terjadi pada daerah Sulawesi Selatan, saat ini data volume sampah menunjukan bahwa jumlah sampah setiap harinya mencapai 1.000ton/hari, adapun sampah yang tidak diolah yaitu mencapai 425 ton/hari, angka ini akan terus meningkat setiap tahunnya, mengingat bahwa penduduk Indonesia semakin tahun akan semakin bertambah dan akan berpengaruh besar terhadap peningkatan volume sampah khususnya sampah anorganik (Kementrian Lingkungan Hidup dan Kehutanan RI, 2018).

Adapun berdasarkan data dari Dinas Lingkungan Hidup Kota Palopo, volume sampah pada wilayah Kota Palopo pada tahun 2017-2018 mengalami peningkatan. Pada tahun 2017 volume sampah mencapai $25.634 \mathrm{~kg}$ khusus sampah anorganik per harinya dan mengalami peningkatan ditahun 2018 yaitu sebanyak 28.046kg. Adapun estimasi sampah di Indonesia pada tahun 2019 mengalami peningkatan mencapai 68 juta ton, dan untuk di kota Palopo sendiri pada tahun 2017, sedikitnya terdapat 6.000 lembar kantong plastik dan gelas air minum kemasan per hari. Data ini diperkirakan akan terus meningkat setiap tahunnya.

Program Botolo'ku diadopsi dari bahasa lokal yang digunakan di Kota Palopo yaitu botol minuman yang penggunaannya dapat digunakan dalam jangka waktu yang lama. Program Botolo'ku mencakup metode pelaksanaan sosialisasi penggunaan botol minuman pengganti botol plastik sekali pakai yang sering digunakan. 
Berangkat dari permasalahan di atas, tim peneliti mengajukan tema Efektivitas Program Botolo'ku. terhadap Peningkatan Pengetahuan dan Sikap dalam Upaya Pengurangan Sampah Botol Plastik di Sekolah Kota Palopo.

\section{METODE PENELITIAN}

Desain penelitian ini adalah quasi eksperimental (eksperimen semu), dengan rancangan non equivalent control group design (Creswell, 2016). Penelitian untuk mencari tahu penjelasan dari objek penelitian tentang Efektivitas Program "Botolo'ku" Terhadap Peningkatan Pengetahuan dan Sikap dalam Upaya Pengurangan Sampah Botol Plastik di Sekolah Kota Palopo. Populasi dalam penelitian ini adalah sekolah yang berada di Kota Palopo sebanyak 2 sekolah dengan pembagian 1 sekolah yang diberi perlakuan Program Botolo'ku dan 1 sekolah tidak diberi perlakuan Program Botolo'ku. Dengan jumlah masingmasing sampel sebanyak 35 siswa. Pelaksanaan penelitian ini dilakukan selama 2 bulan. Instrumen dalam penelitian ini menggunakan koesioner untuk melihat pengetahuan dan sikap siswa terhadap program botolo'ku. Data yang diperoleh dari responden akan diolah dan dianalisis menggunakan analisis univariat dan bivariat. Pada uji bivariat, yang digunakan adalah uji $t$ sampel berpasangan jika data berdistribusi normal tetapi jika data tidak berdistribusi normal uji yang digunakan adalah uji wilcoxon.

\section{HASIL DAN PEMBAHASAN}

\section{Hasil Penelitian}

Penelitian ini dilaksanakan selama 2 bulan. Responden dalam penelitian ini adalah siswa SMAN 4 Palopo sebagai kelompok eksperimen yang berjumlah 35 siswa dan siswa SMAN 2 Palopo sebanyak 35 siswa.

\section{Uji Univariat}

Sampel pada penelitian ini sebanyak 70 siswa yang terdiri dari 2 kelompok yaitu 35 orang siswa dari SMAN 4 Palopo yang diberikan perlakuan dan 35 siswa dari SMAN 2 Palopo yang tidak diberikan perlakuan (Program Botolo'ku). Gambaran karakteristik responden dapat dilihat pada tabel 1 berikut. 
Jurnal Kesehatan Karya Husada, No 9 Vol 1 Tahun 2021

PISSN 2337649X/EISSN 2655-8874

lshak, Indra Amanah AN "Efektivitas Program "Botolo'ku" Terhadap Peningkatan Pengetahuan dan

Sikap dalam Upaya Pengurangan Sampah Botol Plastik" (hal 11-22)

Tabel 1. Distribusi Responden Berdasarkan Umur di SMAN 4 Kota Palopo (Kelompok Eksperimen) dan SMAN 2 Palopo (Kelompok Kontrol) Tahun 2020

\begin{tabular}{rcccc}
\hline \multirow{2}{*}{ Umur } & \multicolumn{2}{c}{ Kelompok Eksperimen } & \multicolumn{2}{c}{ Kelompok Kontrol } \\
\cline { 2 - 5 } & $\begin{array}{c}\text { Frekuensi } \\
(\mathrm{f})\end{array}$ & $\begin{array}{c}\text { Persentase } \\
(\%)\end{array}$ & $\begin{array}{c}\text { Frekuensi } \\
(\mathrm{f})\end{array}$ & $\begin{array}{c}\text { Persentase } \\
(\%)\end{array}$ \\
\cline { 2 - 5 } 16 & 10 & 28,6 & 7 & 20 \\
17 & 20 & 57,1 & 21 & 60 \\
18 & 5 & 14,3 & 7 & 20 \\
\hline \multirow{2}{*}{ Total } & 35 & 100,0 & 35 & 100,0 \\
\hline
\end{tabular}

Sumber : Data Primer, 2020

Tabel 1 menunjukkan bahwa dari pada kelompok kontrol persentase 35 siswa yang diteliti dari kelompok umur yang paling tinggi adalah umur eksperimen diperoleh hasil persentase 17 tahun yaitu sebanyak 21 (60\%) umur yang paling tinggi adalah umur siswa dan persentase umur yang paling 17 tahun yaitu sebanyak $20(57,1 \%)$ rendah adalah umur 16 dan 17 tahun siswa dan persentase umur yang paling yaitu masing-masing sebanyak 7 (20\%) rendah adalah umur 18 tahun yaitu siswa. sebanyak $5(14,3 \%)$ siswa sedangkan

Tabel 2. Distribusi Responden Berdasarkan Jenis Kelamin di SMAN 4 Kota Palopo (Kelompok Eksperimen) dan SMAN 2 Palopo (Kelompok Kontrol) Tahun 2020

\begin{tabular}{ccccc}
\hline \multirow{2}{*}{ Jenis Kelamin } & \multicolumn{2}{c}{ Kelompok Eksperimen } & \multicolumn{2}{l}{ Kelompok Kontrol } \\
\cline { 2 - 5 } \cline { 4 - 5 } & Frekuensi (f) & Persentase (\%) & Frekuensi (f) & Persentase (\%) \\
\hline Perempuan & 20 & 57,1 & 29 & 82,9 \\
Laki-Laki & 15 & 42,9 & 6 & 17,1 \\
\hline Total & 35 & 100,0 & 35 & 100 \\
\hline Sumber : Data Primer, 2020 & &
\end{tabular}

Tabel 2 menunjukkan bahwa dari 32 responden yang diteliti dari kelompok eksperimen distribusi jenis kelamin perempuan yaitu sebanyak 20 $(57,1 \%)$ siswa dan jenis kelamin lakilaki yaitu sebanyak 15 (42,9\%) siswa. sedangkan pada kelompok kontrol jenis kelamin perempuan yaitu sebanyak $29(82,9 \%)$ siswa dan jenis kelamin laki-laki yaitu sebanyak 6 $(17,1 \%)$ siswa 


\section{Hasil Analisis Data}

Analisis data dilakukan pada hasil uji prasyarat dan hasil uji hipotesis dari data hasil penelitian yang telah dilakukan. Uji prasyarat digunakan untuk menentukan apakah data yang diperoleh terdistribusi normal. Setelah uji prasyarat dilakukan, maka langkah selanjutnya menganalisis hasil uji hipotesis.

\section{Uji Normalitas}

Tahapan pertama menggunakan uji normalitas data dimaksudkan untuk memperlihatkan bahwa data sampel berasal dari populasi yang berdistribusi normal. Uji ini dilakukan dengan menggunakan SPSS 20. Uji normalitas data menggunakan ShapiroWilk. Pedoman pengambilan keputusan adalah jika nilai signifikan (p-value) $<0,05$ data tidak normal dan sebaliknya jika nilai signifikansi (pvalue) > 0,05 data dikatakan normal (Basrowi dan Soenyono, 2007:78). Berikut ini hasil data yang diperoleh:

Tabel 3. Hasil Uji Normalitas Data Pre Test Pengetahuan

\begin{tabular}{lllll}
\hline Kelompok & $\begin{array}{l}\text { Statisti } \\
\mathrm{c}\end{array}$ & Df & p-value & Ket \\
\hline Eksperime & .954 & 35 & 0,331 & Normal \\
$\mathrm{n}$ & & & & \\
Kontrol & .960 & 35 & 0,055 & Normal \\
\hline
\end{tabular}

Pada tabel 3 di atas diperoleh untuk kelompok eksperimen nilai signifikansi $(\mathrm{p}$-value $)=0,331>0,05$ dan untuk kelas kontrol nilai signifikansi $(\mathrm{p}$-value $)=0,055>0,05$. Dengan demikian sampel tersebut berasal dari populasi yang berdistribusi normal.

Tabel 4. Hasil Uji Normalitas Data Post Test Pengetahuan

\begin{tabular}{|c|c|c|c|c|}
\hline Kelompok & $\begin{array}{l}\text { Statisti } \\
\mathrm{c} \\
\end{array}$ & Df & $\begin{array}{l}\mathrm{p}- \\
\text { value }\end{array}$ & Ket \\
\hline Eksperimen & .939 & 35 & 0,053 & $\begin{array}{l}\text { Norma } \\
1\end{array}$ \\
\hline Kontrol & .949 & 35 & 0,104 & $\begin{array}{l}\text { Norma } \\
1\end{array}$ \\
\hline
\end{tabular}

Pada tabel 4 di atas diperoleh untuk kelompok eksperimen nilai signifikansi $(\mathrm{p}$-value $)=0,053>0,05$ dan untuk kelas kontrol nilai signifikansi $(p$-value $)=0,104>0,05$. Dengan demikian sampel tersebut berasal dari populasi yang berdistribusi normal.

Tabel 5. Hasil Uji Normalitas Data Pre Test Sikap

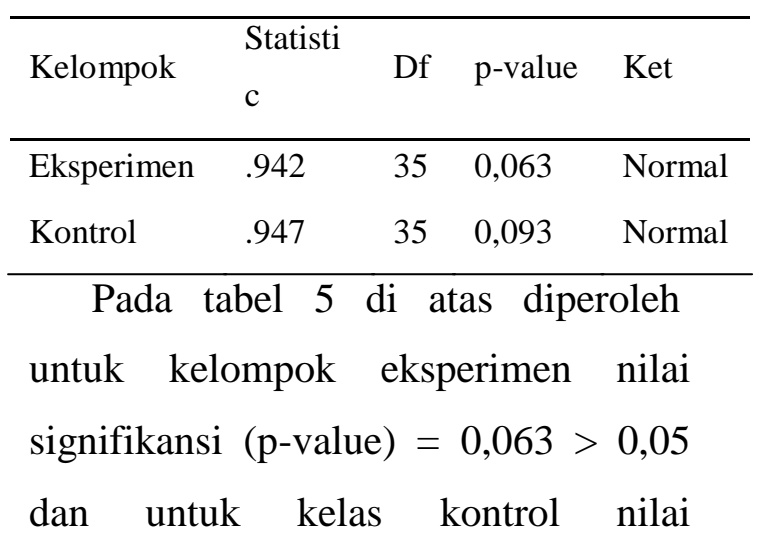


Jurnal Kesehatan Karya Husada, No 9 Vol 1 Tahun 2021

PISSN 2337649X/EISSN 2655-8874

lshak, Indra Amanah AN "Efektivitas Program "Botolo'ku" Terhadap Peningkatan Pengetahuan dan Sikap dalam Upaya Pengurangan Sampah Botol Plastik" (hal 11-22)

signifikansi $(\mathrm{p}$-value $)=0,093>0,05$.

$\begin{array}{lllll}\text { Kontrol } & .945 & 35 & 0,079 & \text { Norma }\end{array}$

Dengan demikian sampel tersebut

berasal dari populasi yang

berdistribusi normal.

Tabel 6. Hasil Uji Normalitas Data

Post Test Sikap

\begin{tabular}{lllll}
\hline Kelompok & $\begin{array}{l}\text { Statisti } \\
\mathrm{c}\end{array}$ & Df & p-value & Ket \\
\hline Eksperimen & .942 & 35 & 0,065 & Normal
\end{tabular}

\begin{tabular}{l}
\hline Pada tabel 6 di atas diperoleh \\
\hline untuk kelompok eksperimen nilai \\
signifikansi (p-value) $=0,065>0,05$ \\
dan untuk kelas kontrol nilai \\
signifikansi (p-value) $=0,079>0,05$. \\
Dengan demikian sampel tersebut \\
berasal dari populasi yang \\
berdistribusi normal.
\end{tabular}

\section{Uji Hipotetis}

\section{Uji Efektivitas Variabel Pengetahuan}

Tabel 7. Uji t Efektivitas Kelompok Eksperimen dan Kelompok Kontrol Variabel Pengetahuan

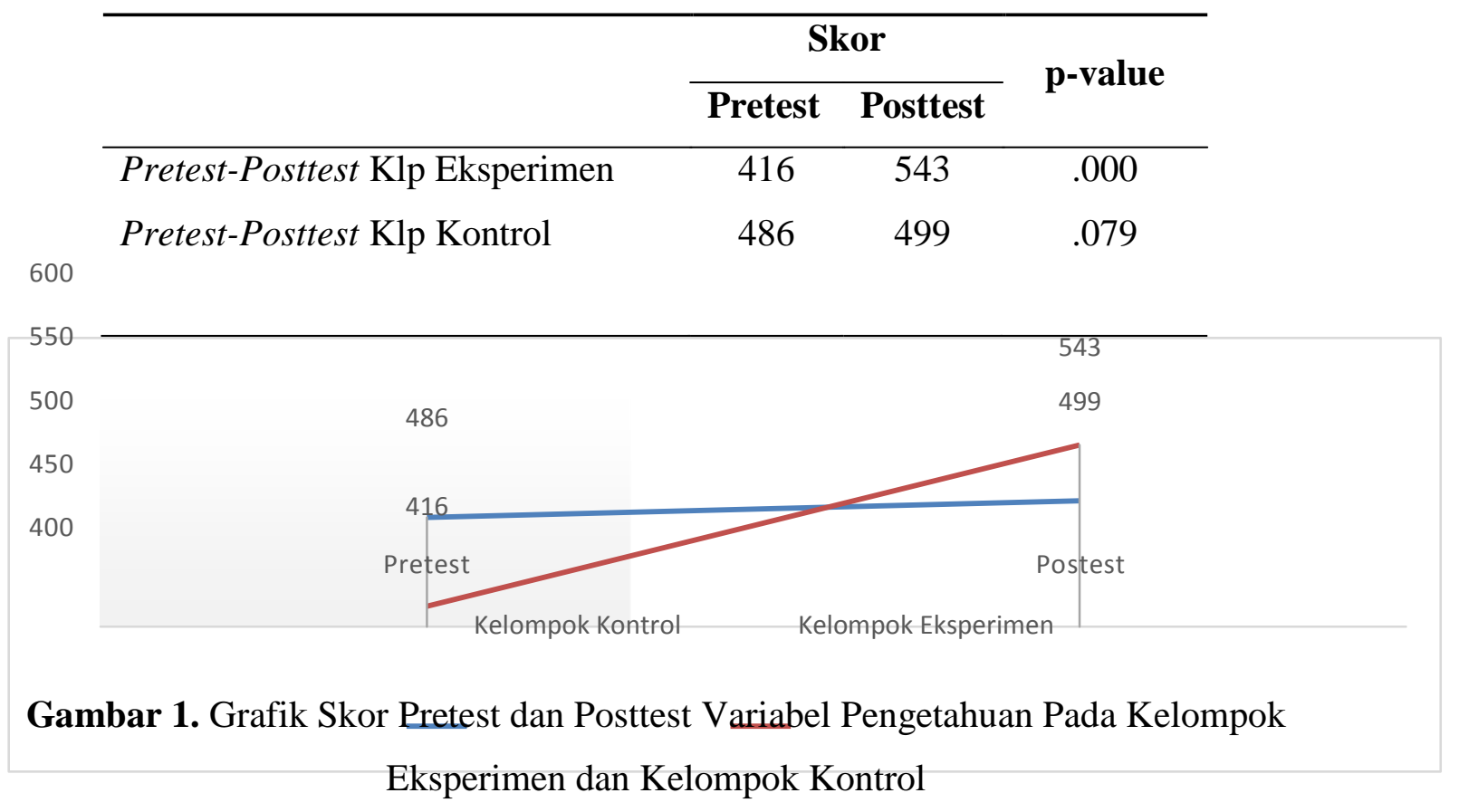



Berdasarkan tabel 7 di atas, uji t diberikan Program "Botolo'ku" di untuk kelompok eksperimen Sekolah Kota Palopo. Sementara untuk menunjukkan bahwa nilai p-value uji t kelompok kontrol diperoleh nilai sebelum (pretest) dan sesudah $\mathrm{p}$-value $=0,079$. Nilai ini lebih besar (posttest) diberikan Program dari 0,05 ( $\mathrm{p}=0,079<0,05)$, maka Ho "Botolo'ku" di Sekolah Kota Palopo diterima. Maka dapat disimpulkan yaitu $\mathrm{p}=0,000$. Nilai ini lebih kecil bahwa tidak ada perbedaan atau dari 0,05 (p-value $=0,000<0,05), \quad$ peningkatan pengetahuan pada maka Ho ditolak. Maka dapat kelompok kontrol sebelum (pretest) disimpulkan bahwa ada perbedaan atau dan sesudah (posttest) diberikan peningkatan pengetahuan pada Program "Botolo'ku" di Sekolah Kota kelompok eksperimen sebelum Palopo.

(pretest) dan sesudah (posttest)

\section{Uji Efektivitas Variabel Sikap}

Tabel 8. Uji t Efektivitas Kelompok Eksperimen Dan Kelompok Kontrol Variabel Sikap

\begin{tabular}{lccc}
\hline & \multicolumn{2}{c}{ Skor } & \multirow{2}{*}{ p-value } \\
\cline { 2 - 3 } & Pretest & Posttest & \\
\hline Pretest-Posttest Klp Eksperimen & 377 & 466 & .000 \\
Pretest-Posttest Klp Kontrol & 398 & 418 & .171 \\
\hline
\end{tabular}

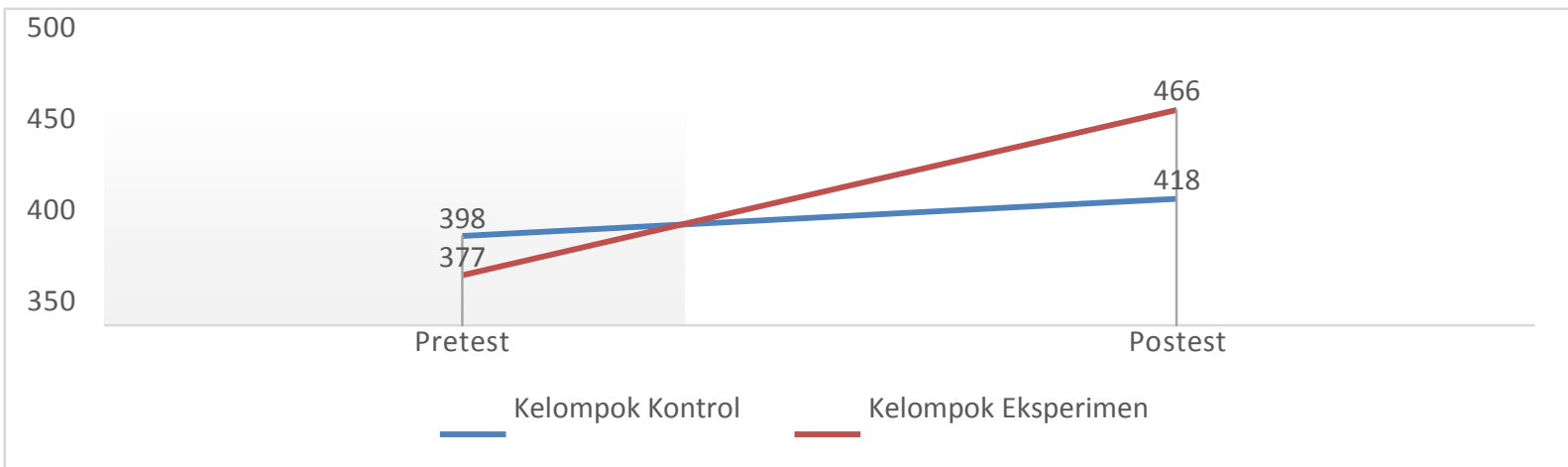

Gambar 2. Grafik Skor Pretest dan Posttest Variabel Sikap Pada Kelompok Eksperimen dan Kelompok Kontrol 
Jurnal Kesehatan Karya Husada, No 9 Vol 1 Tahun 2021

PISSN 2337649X/EISSN 2655-8874

Ishak, Indra Amanah AN “Efektivitas Program "Botolo'ku” Terhadap Peningkatan Pengetahuan dan Sikap dalam Upaya Pengurangan Sampah Botol Plastik" (hal 11-22)

Berdasarkan tabel $8 \mathrm{di}$ atas, uji t seeseorang (ovent behavior). Dari untuk kelompok eksperimen pengalaman dan penelitian ternyata menunjukkan bahwa nilai p-value perilaku yang didasari oleh sebelum (pretest) dan sesudah pengetahuan akan lebih langgeng (posttest) diberikan Program daripada perilaku yang tidak didasari

"Botolo'ku" di Sekolah Kota Palopo yaitu $\mathrm{p}=0,000$. Nilai ini lebih kecil dari $0,05(\mathrm{p}$-value $=0,000<0,05)$, maka Ho ditolak. Maka dapat disimpulkan bahwa ada perbedaan atau peningkatan sikap pada kelompok eksperimen sebelum (pretest) dan sesudah (posttest) diberikan Program "Botolo'ku" di Sekolah Kota Palopo. Sementara untuk uji t kelompok kontrol diperoleh $\mathrm{p}$-value $=0,171$. Nilai ini lebih besar dari $0,05(\mathrm{p}=0,171<0,05)$, maka Ho diterima. Maka dapat disimpulkan bahwa tidak ada perbedaan atau peningkatan sikap pada kelompok kontrol sebelum (pretest) dan sesudah (posttest) diberikan Program “Botolo'ku” di Sekolah Kota Palopo.

\section{Hasil Penelitian}

1. Efektivitas program "Botolo'ku" terhadap peningkatan pengetahuan dalam upaya pengurangan sampah botol plastik

Pengetahuan atau kognitif merupakan domain yang sangat penting untuk terbentuknya tindakan oleh pengetahuan (Notoatmodjo, 2003:

Wawan dan Dewi, 2011).

Pada penelitian ini menunjukkan bahwa program "Botolo'ku” efektif terhadap peningkatan pengetahuan dalam upaya pengurangan sampah botol plastik. Berdasarkan pada tabel 7 menunjukkan nilai $\mathrm{p}<, 05(\mathrm{p}<\alpha)$, dapat diartikan bahwa ada peningkatan pengetahuan sebelum dan sesudah diberikan Program "Botolo'ku". Sedangkan pada kelompok kontrol diperoleh hasil uji $\mathrm{t}$ dengan nilai $\mathrm{p}>, 05$ $(p>\alpha)$, dapat diartikan bahwa tidak ada peningkatan pengetahuan pada kelompok kontrol yang tidak diberikan perlakuan Program "Botolo 'ku".

Penerapan program “Botolo'ku” dalam upaya pengurangan sampah botol plastik menunjukkan hasil yaitu sebelum diberikan perlakuan pada kelompok eksperimen siswa belum mengetahui bahaya, cara mengurangi sampah dan dampak dari sampah anorganik bagi kesehatan dan lingkungan, dan setelah diberikan perlakuan berupa sosialisasi dan 
penerapan program "Botolo'ku" siswa mengalami peningkatan pengetahuan dalam upaya pengurangan sampah botol plastik. Dan untuk kelompok kontrol (tidak diberikan perlakuan) setelah diberikan pretest dan posttest siswa tidak mengalami peningkatan pengetahuan terkait penerapan program "Botolo 'ku" dalam upaya pengurangan sampah botol plastik.

Penelitian ini sejalan dengan penelitian yang dilakukan oleh Musfirah, (2018) yang menunjukan bahwa pengetahuan siswa mengalami perubahan atau peningkatan pengetahuan setelah diberikan penyuluhan dan pelatihan pengolahan sampah konsep 3R yang dilakukan pada siswa SMK 3 Muhammadiyah Yogyakarta kelas $\mathrm{X}$ hal ini dapat dilihat dari nilai variabel pengetahuan (p-value $=0,015)$ yang berarti bahwa ada perbedaan pada pengetahuan siswa dalam pengelolaan sampah konsep 3R antara sebelum dan sesudah dilaksanakan penyuluhan dan pelatihan.

Penelitian yang dilakukan oleh Ruhmawati at.el (2017) menunjukkan bahwa terjadi perubahan atau peningkatan pengetahuan setelah diberikan intervensi berupa pemberdayaan model keluarga mencakup konseling, pelatihan, dan pendampingan yang dilakukan pada seluruh kepala keluarga di RW 06 Kelurahan Tamansari Kota Bandung hal ini dapat dilihat dari nilai variabel pengetahuan $(p$-value $=0,001)$ yang berarti bahwa ada perbedaan pada pengetahuan responden dalam pengelolaan sampah antara sebelum dan sesudah dilaksanakan intervensi pemberdayaan.

Selain itu penelitian yang dilakukan oleh Fauzi at.el (2020) juga memiliki kemaknaan sejalan, hasil penelitian menunjukkan bahwa terjadi perubahan atau peningkatan pengetahuan dari tidak tahu menjadi tahu ini membuktikan bahwa pelatihan ini memberikan pengaruh kepada tingkat pengetahuan masyarakat di Kecamatan Bunga Raya dalam upaya mengurangi sampah plastik dengan metode ecobrick. Hal ini dapat dilihat dari rerata nilai pretest dan posttest variabel pengetahuan masyarakat yang jauh berbeda yaitu 30,6 pada pretest dan 80,5 pada posttest.

2. Efektivitas program “Botolo'ku”
terhadap peningkatan sikap dalam
upaya pengurangan sampah botol
plastik
terhadap peningkatan sikap dalam upaya pengurangan sampah botol plastik 
Jurnal Kesehatan Karya Husada, No 9 Vol 1 Tahun 2021

PISSN 2337649X/EISSN 2655-8874

Ishak, Indra Amanah AN “Efektivitas Program "Botolo'ku” Terhadap Peningkatan Pengetahuan dan Sikap dalam Upaya Pengurangan Sampah Botol Plastik" (hal 11-22)

Sikap merupakan reaksi atau respon mencerminkan adanya pengaruh oleh yang masih tertutup dari seseorang sosialisasi dan penerapan program terhadap suatu stimulus atau obyek. "Botolo'ku" yang diberikan, Manifestasi dari sikap tidak dapat peningkatan sikap mengenai upaya dilihat, tetapi hanya ditafsirkan terlebih dahulu dari perilaku yang tertutup. pengurangan sampah botol plastik Dalam kehidupan sehari-hari pengertian sikap adalah reaksi yang bersifat emosional terhadap stimulus sosial (Adnani, 2011).

Pada penelitian ini menunjukkan bahwa program "Botolo'ku" efektif terhadap peningkatan sikap dalam upaya pengurangan sampah botol plastik dengan adanya perbedaan sikap sebelum dan sesudah diberikan program "Botolo'ku". Berdasarkan pada tabel 8 diperoleh hasil uji $\mathrm{t}$ menunjukkan nilai $\mathrm{p}<, 05(\mathrm{p}<\alpha)$, dapat diartikan bahwa ada peningkatan pengetahuan sebelum dan sesudah diberikan Program "Botolo'ku". terjadi karena siswa dapat dengan mudah memahami apa yang peneliti sampaikan dalam sosialisasi dan dengan rasa senang menjalankan program "Botolo'ku" yang peneliti terapkan.

Penelitian ini sejalan dengan penelitian yang dilakukan oleh Ruhmawati at.el (2017) menunjukkan bahwa terjadi perubahan atau sikap setelah diberikan intervensi berupa pemberdayaan model keluarga mencakup konseling, pelatihan, dan pendampingan yang dilakukan pada seluruh kepala keluarga di RW 06 Kelurahan Tamansari Kota Bandung. Hal ini dapat dilihat dari nilai variabel Sedangkan pada kelompok kontrol diperoleh hasil nilai $\mathrm{p}>, 05(\mathrm{p}>\alpha)$, dapat diartikan bahwa tidak ada peningkatan pengetahuan pada kelompok kontrol yang tidak diberikan perlakuan Program “Botolo 'ku”.

Penelitian ini dilakukan dengan selisih pretest dan posttest selama dua bulan. Peningkatan sikap dalam upaya pengurangan sampah botol plastik sikap $(p$-value $=0,005)$ yang berarti bahwa ada perbedaan pada sikap responden dalam pengelolaan sampah antara sebelum dan sesudah dilaksanakan intervensi pemberdayaan.

Selain itu penelitian yang dilakukan oleh Diniaty at.el (2019) menunjukkan bahwa terjadi perubahan sikap setelah diberikan penyuluhan dan pelatihan pengolahan sampah menjadi produk 
yang bermanfaat terhadap masyarakat di kelurahan tangkerang barat tepatnya di RW 04 RT 06 yang terdapat Rumah Kelola Sampah (RKS). Hal ini dapat dilihat dari nilai variabel sikap ( $p$-value $=0,00)$ yang artinya bahwa ada perbedaan sikap pada masyarakat dalam pengelolaan sampah antara sebelum dan sesudah diberikan penyuluhan dan pelatihan pengelolaan sampah.

\section{SIMPULAN dan SARAN}

\section{Kesimpulan}

Program "botolo' $k u$ " efektif terhadap peningkatan pengetahuan dan sikap dalam upaya pengurangan sampah plastik di Sekolah Kota Palopo

\section{Saran}

Diharapkan program botolo'ku dapat diaplikasikan secara merata di tiap sekolah. sehingga dapat mengurangi sampah botol plastik.

\section{DAFTAR PUSTAKA}

Luthfia Ayu Azanella. "Sampah Plastik Dunia dalam Angka", https://internasional.kom pas.com/read/2018/11/21/184656 01/sampah-plastik-dunia-dalamangka? page $=$ all. Di akses pada tanggal 18 agustus 201910.00 WITA.
Silkyane Seizaria. (2017). Eksplorasi Limbah Gelas Plastik Untuk Diterapkan Pada Produk Fesyen, Universitas Telkom, Bandung. ISSN : 2355-9349. Vol.4, No.3 Desember 2017

Sulistiyorini, N.R; Darwis, R.S; Gutama, A.S. (2015). "Partisipasi Masyarakat Dalam Pengelolaan Sampah di Lingkungan Margaluyu Kelurahan Cicurug", Share Sosial Work Jurnal Volume 5 Nomor 1, ISSN:2339-0042.

Our World in Data, https://ourworldindata.org/

Kamali, S.,T, Sumarlan, I.,\& Fahrurazi. (2017). Pengolahan Sampah Plastik Metode Cracking di Kelurahan Kelayu Jorong Lombok Timur. Universitas Mataram. Jalan Majapahit No 62, 7,(2), 116-119.

Kementrian Lingkungan Hidup dan Kehutanan RI. (2018). Sistem Informasi Pengelolaan Sampah Nasional.

Dinas Lingkungan Hidup Kota Palopo. (2018). Volume Sampah Kota Palopo.

Creswell JW. Research Design Pendekatan Metode Kualitatif, Kuantitatif, dan Campuran. Keenam. Yogyakarta: Pustaka Pelajar; 2016.

Adnani, H. (2011). Ilmu Kesehatan Masyarakat. Yogyakarta: Nuha Medika

Wawan, A., \& Dewi, M. (2011). Pengetahuan, Sikap dan Perilaku 
Jurnal Kesehatan Karya Husada, No 9 Vol 1 Tahun 2021

PISSN 2337649X/EISSN 2655-8874

lshak, Indra Amanah AN "Efektivitas Program "Botolo'ku" Terhadap Peningkatan Pengetahuan dan Sikap dalam Upaya Pengurangan Sampah Botol Plastik" (hal 11-22)

Manusia. (W. A \& D. M, Eds.)

(II). Yogyakarta: Nuha Medika.

Musfirah. (2018). Pengaruh

Penyuluhan Terhadap

Pengetahuan Dan Intensi Perilaku

Pengelolaan Sampah Konsep 3R

Siswa Kelas X Sekolah

Menengah Kejuruan, Yogyakarta,

Indonesia. Jurnal Publikasi

Kesehatan Masyarakat Indonesia, $5(2)$

Fauzi, m., Sumiarsih, e., adriman., rusliadi, \& hasibuan, i, f. (2020). Pemberdayaan masyarakat melalui pelatihan pembuatan ecobrick sebagai upaya mengurangi sampah plastik di kecamatan Bunga Raya. Riau Journal of empowerment, 3(2), 87-96.

Ruhmawati, T., Karmini, M., Tjahjani, D. (2017). Peningkatan Pengetahuan Dan Sikap Kepala Keluarga Tentang Pengelolaan Sampah Melalui Pemberdayaan Keluarga Di Kelurahan Tamansari Kota Bandung. Jurnal Kesehatan Lingkungan Indonesia, 16(1)

Diniaty, D., Permata, G, E., Alpian, D, I. (2019). Pengaruh Pengetahuan, Sikap, Dan Tindakan Masyarakat Terhadap Keberadaan Rumah Kelola Sampah Menggunakan Metode SEM (Studi Kasus : Kelurahan Tangkerang Barat). Jurnal Hasil Penelitian Dan Karya Ilmiah Dalam Bidang Teknik Industri, 5(1) 